\title{
MRI and polysomnographic findings of patients affected by post-stroke sleep apnea
}

\author{
Maria Luisa Sacchetti ${ }^{1 \#}$, Maria Teresa Di Mascio, Marco Fiorelli ${ }^{1}$, Giacomo Della Marca ${ }^{2}$, \\ Anna Losurdo ${ }^{2}$, Gennaro Russo ${ }^{1}$, Danilo Toni ${ }^{1}$, Antonio Minni ${ }^{3}$, Emanuele Tinelli ${ }^{1}$, \\ Francesca Caramia ${ }^{1}$ \\ ${ }^{1}$ Department of Neurology and Psychiatry, Sapienza University, Rome, Italy; \\ ${ }^{\#}$ Corresponding Author: marialuisa.sacchetti@uniroma1.it \\ ${ }^{2}$ Sleep Unit, Institute of Neurology, Catholic University, Rome, Italy \\ ${ }^{3}$ Department of Sensory Organs, Sapienza University of Rome, Rome, Italy \\ Received 4 June 2013; revised 15 July 2013; accepted 3 August 2013 \\ Copyright (C) 2013 Maria Luisa Sacchetti et al. This is an open access article distributed under the Creative Commons Attribution \\ License, which permits unrestricted use, distribution, and reproduction in any medium, provided the original work is properly cited.
}

\section{ABSTRACT}

Aim: The aim of our study was to compare characteristics of stroke patients who presented Obstructive Sleep Apnea/Hypopnea (OSAH) to those of cases that presented Central Sleep Apnea/Hypopnea (CSAH) events at PSG, and to investigate relationships between the type of breathing disturb during sleep and the location of brain damage. Methods: Thirty four patients were submitted to clinical, neuroradiological and polisomnographyc study (PSG) after 4 months of stroke. A Sleep Disordered Breathing (SDB) was diagnosed in all cases with an AHI > 5 . Patients were classified as affected by predominantly OSAH (pOSAH), or predominantly CSAH ( $p C S A H)$. Comparisons were made among the groups and correlation analyses were done in each group. Significance was set at $p<0.005$. Results: Twenty six patients with ischemic strokes had a SDB during sleep (56\% embolic, $31 \%$ lacunar, $8 \%$ large artery, $8 \%$ with undetermined cause). The $61 \%$ of them showed pOSAH. Except for age, no statistical differences were found between the two groups as to clinical findings, risk factors for stroke, PSG data, or location of brain lesion. Correlation analysis outlined that in POSAH cases the time interval from stroke to PSG $(\Delta t)$ was inversely related to both TST $(p=0.017)$ and TSP $(p=0.039)$; in $p C S A H s$ it was inversely related to SE Index $(p=$ $0.021)$ and directly related to both ODI $(p=0.016)$ and with the $n$. of arrhythmias/h sleep $(p=0.033)$. In pCSAH, AHI did not correlate with ODI. Conclusions: Our data suggest that among cases

"Disclosure: The authors have no conflicts of interest to declare. with post stroke SDB is included 3 different subgroups of cases: OSAHs who terminate the obstruction by arousal, OSAHs who do not arise and alternate obstructive to central events, and CSAHs due to the direct effect of stroke on the breathing network; in a forth subgroup of cases, the microstructure of sleep might be altered, with the consequent occurrence of sleep-related events. Further studies are needed to clarify these hypotheses as well as the role of poststroke depression on the nature and occurrence of SDB after stroke.

Keywords: Sleep Apnea-Stroke; Magnetic Risonance Imaging-Polysomnography

\section{INTRODUCTION}

Prevalence of Sleep-disordered breathing (SDB) in patients with first-ever stroke or TIA is higher than in normal populations [1]. The disturbance more frequently recognized in these cases is a "mixed" rather than purely obstructive or central disorder [1,2]. Characteristics of SDB in patients with stable stroke have not been studied yet. In order to define the clinical and instrumental profile of patients affected by obstructive sleep apnea-hypopnea (OSAH) and to compare them with the profile of cases affected by a Central Sleep Apnea/Hypopnea $(\mathrm{CSAH})$, we report here data on a series of 34 cases with stable stroke, studied at Sapienza, University of Rome.

\section{METHODS}

\subsection{Patients and Diagnostic Work-Up}

A consecutive series of patients with acute stroke, ad- 
mitted to the Stroke Unit of Policlinico Umberto I University Hospital, were screened. After the exclusion of patients who did not consent to enter the study, elected cases were submitted to both clinical and instrumental diagnostic tests. Details on the study protocol have been reported in a previous publication [3]. Briefly, at stroke onset and at discharge from the Stroke Unit, and then at 4 months of stroke onset, participants were submitted to a complete clinical and diagnostic work-up. Stroke workup included estimation of stroke severity (National Institutes of Health Stroke Scale [NIHSS], assessment of cardiovascular risk factors by means of doppler ultrasonography and echocardiography; in order to confirm the diagnosis a brain computer tomography (CT) was performed; conventional magnetic resonance imaging (MRI), was performed in all subjects to investigate relationships between the site of cerebral lesion and the type of sleep breathing disturb $[4,5]$. Etiology of stroke was classified according to the Trial of Org 10172 in Acute Treatment (TOAST) study [6]. The site of cerebral lesion was classified as frontal-precentral, deep MCA, thalamic, hypothalamic, brainstem, or other location. Sleep work-up included daytime sleepiness estimation with the Epworth Sleepiness Scale questionnaire (ESS) [7], screening of symptoms other than daytime sleepiness [8], and overnight home based polysomnography (PSG) [9]. PSG was performed by the hand-held 34 channel Morpheus Ambulatory recorder by Micromed ${ }^{\circledR}$ S.r.l. Ambulatory 34 Channels PSG was preferred to standard laboratory recording in order to allow the patients to sleep in their home setting, without needs of adaptation. The following parameters were recorded: 1) body position; 2) rib-gage and abdominal respiratory efforts (Dual thoracoabdominal RIPrespiratory inductance Plethysmography-belts by Micromed $^{\circledR}$ S.r.l. Accessories EPM 915x A); oro-nasal airflow (thermistor transducer by Micromed ${ }^{\circledR}$ S.r.l. Accessories EPMs 1450-S ); 4) oxygen saturation (finger pulse oximeter sensor); 5) 8 EEG channels (2 frontal, 2 central, 2 temporal, 2 occipital); 6) right and left electrooculography, and 7) sub mental electromyography from surface electrodes; 8) Electrocardiogram (EKG). Morpheus was retrieved the following morning the sensors were attached; data were downloaded to the SystemPlus Evolution software, and subsequently analyzed with dedicated software Rembrandt SleepView, by a sleep expert. Were considered adequate only PSGs with a total recording time $>4$ hours and a TST $<2$ hours, during which both NREM and REM episodes were present. Sleep-stage scoring was done visually according to standard criteria [9].

\subsection{Definitions}

Apnea was defined as the cessation of airflow for at least 10 seconds. An apnea was scored as obstructive for absent nasal pressure fluctuations with continued thoracic and/or abdominal efforts; it was scored as central in absence of thoracic and/or abdominal efforts. A hypopnoea was scored for $\geq 50 \%$ reductions in nasal pressure for $\geq 10$ seconds. The nasal pressure signal was considered to be unreliable during periods of mouth breathing, as detected from the oral thermister signal. During these periods, hypopnoeas were scored as $\geq 50 \%$ decrease in both thoracic and abdominal movement signals for $\geq 10$ seconds. The number of apneas and of apneas plus hypopneas per hour of sleep was expressed as apnea-hypopnea index (AHI). Sleep apnea was diagnosed when the AHI was $>5$ [7]. A CSA was identified by the absence of chest wall movement. An OSA was identified in cases with a clear dissociation between preserved chest wall movement and airflow pattern. Central Periodic Breathing (CPB) was defined so as recommended [10]. Arousals were defined as "an abrupt change from a "deeper" stage of non-REM (NREM) sleep to a "lighter" stage, or from REM sleep toward wakefulness, with the possibility of awakening as the final outcome" [11]. Arrhythmias were defined as any disturbances of the normal rhythmic beating of the heart according to [12].

\subsection{Statistical Analysis}

On the bases of PSG study, 2 groups were identified: cases with predominantly OSAHS ( $p \mathrm{OSAH})$, and cases with predominantly CSAHS ( $p$ CSAH). Groups were compared in terms of: age, sex, time from stroke to PSG evaluation (days); NIH-SS at entry and at discharge from Stroke Unit; Body Mass Index (BMI), ESS, Total Sleep Time (TST); Total Sleep Period (TSP); Sleep Efficiency Index; arousals/h sleep; sleep phases; arrhythmias/h of sleep; oxygen desaturation index (ODI), causes of stroke, and sites of cerebral lesions. Patient's demographic data, risk factors for stroke, and sleep study data are expressed as mean and $\mathrm{SD}$ or percentages. Categorical comparisons were analysed using the $\chi^{2}$ test, and contingency analysis of $2 \times 2$ tables was performed via Fischer exact test. Continuous data were analyzed using ANOVA. Correlation analyses were done with non-parametric tests (Spearman's Rho). Statistical significance was set at $\mathrm{p}<0.05$. Statistical analysis was performed with Statistical Package of Social Sciences (SPSS) version 18.0 for Window.

\section{RESULTS}

After the exclusion of cases that did not consent, 34 patients entered the study. All cases were affected by a first ever ischemic stroke confirmed by brain computer tomography (CT) or magnetic resonance imaging (MRI). Patients' mean age was $64.7 \pm 13$. Twenty six cases $(76 \%)$ had a SDB. The $56 \%(\mathrm{n}=14)$ were embolic in nature, the $31 \%(\mathrm{n}=8)$ were lacunar, in the $8 \%(\mathrm{n}=2)$ of cases a 
large artery cause was revealed, and in $8 \%(n=2)$ the cause of stroke was undetermined. The BMI was $28 \pm 5$ $\mathrm{kg} / \mathrm{m}^{2}$ (range 21 to 43 ; median 26.5). Nine cases were overweight. The mean AHI was $15 \pm 8$ (range 5 to 35 ; median 12.7). MRI at 4 months of stroke revealed an infarct located in the a thalamus in 1 case, in hypothalamus in 4 cases, in the fronto-pre-central region in 10 cases, in deep MCA in 1 case, the brainstem in 3 cases, and in 6 cases the lesion was sited in other locations (Figure 1). ORL evaluation was performed in 22 cases and was abnormal in 12 of them. Twelve cases had an obstruction of the upper airways and in 7 of them the obstruction was combined with an increase in pharyngeal tissue. The PSG study was performed $134.2 \pm 53$ days after stroke onset (range: 87 - 282; median 124.5 days). In all cases a mixed sleep apnea was registered; 16 out of the 26 cases $(61.5 \%)$ had predominantly obstructive events, in the remaining 10 cases $(38.5 \%)$ the events were predominantly central. None of the patients affected by $p$ CSAH showed CPBS. Eight patients with positive ORL evaluation had a $p \mathrm{OSAH}$ at the PSG and 4 cases were affected by $p$ CSAHS. The upper airways obstruction was combined with an increase in pharyngeal tissue in 3 of them; 2 of these 3 cases had also BMI > 30. Patients affected by $p \mathrm{CSAH}$ were significantly older than those with $p \mathrm{OSAH}$. No other significant differences were found between cases with predominantly obstructive events and those with predominantly central ones in demographic data, clinical characteristics, risk factors or causes of stroke. No statistical difference was found between the two groups as respect to the location of the brain lesion (Table 1). Correlation analysis outlined that in $p \mathrm{OSAH}$ cases the time interval from stroke to PSG $(\Delta t)$, was inversely related to both TST $(\mathrm{p}=0.017)$ and TSP $(\mathrm{p}=0.039)$; in $p$ CSAHs it was inversely related to SE Index $(\mathrm{p}=0.021)$ and directly related to both ODI $(\mathrm{p}=0.016)$ and with the $\mathrm{n}$. of arrhythmias/h sleep ( $\mathrm{p}=0.033)$. In $p \mathrm{CSAH}, \mathrm{AHI}$ did not correlate with (Table 2).

\section{DISCUSSION}

In our series of stroke patients affected by sleep apnea, none had pure obstructive or pure central events. Polysomnopraphy in fact demonstrated some mixes of obstructive and central events, predominant obstructive is found in $62 \%$ of cases. One simple explanation is in that obstructive sleep apnea is highly prevalent among stroke cases; in patients which stroke damages the brain areas deputed to breath control, a central disturbance emerges, resulting in mixed sleep apneas. If this hypothesis is true, the location of brain damage of cases affected by CSAH should be different from the site of the lesion of cases affected by OSAH. Similarly to what reported by other authors, in our series, no significant difference was found in the location of infarct damage between the two groups, and no correlations were found between the kind of sleep disordered breathing and stroke topography [13-17].

When comparing cases who presented predominantly obstructive events in the PSG study with those who instead presented mostly central sleep apnea, any significant difference was found as to their clinical characteristics or PSG data, except for age. On the contrary, among some cases with $p \mathrm{CSAH}$ and have the typical clinical profile of cases who manifest an obstructive sleep apnea,

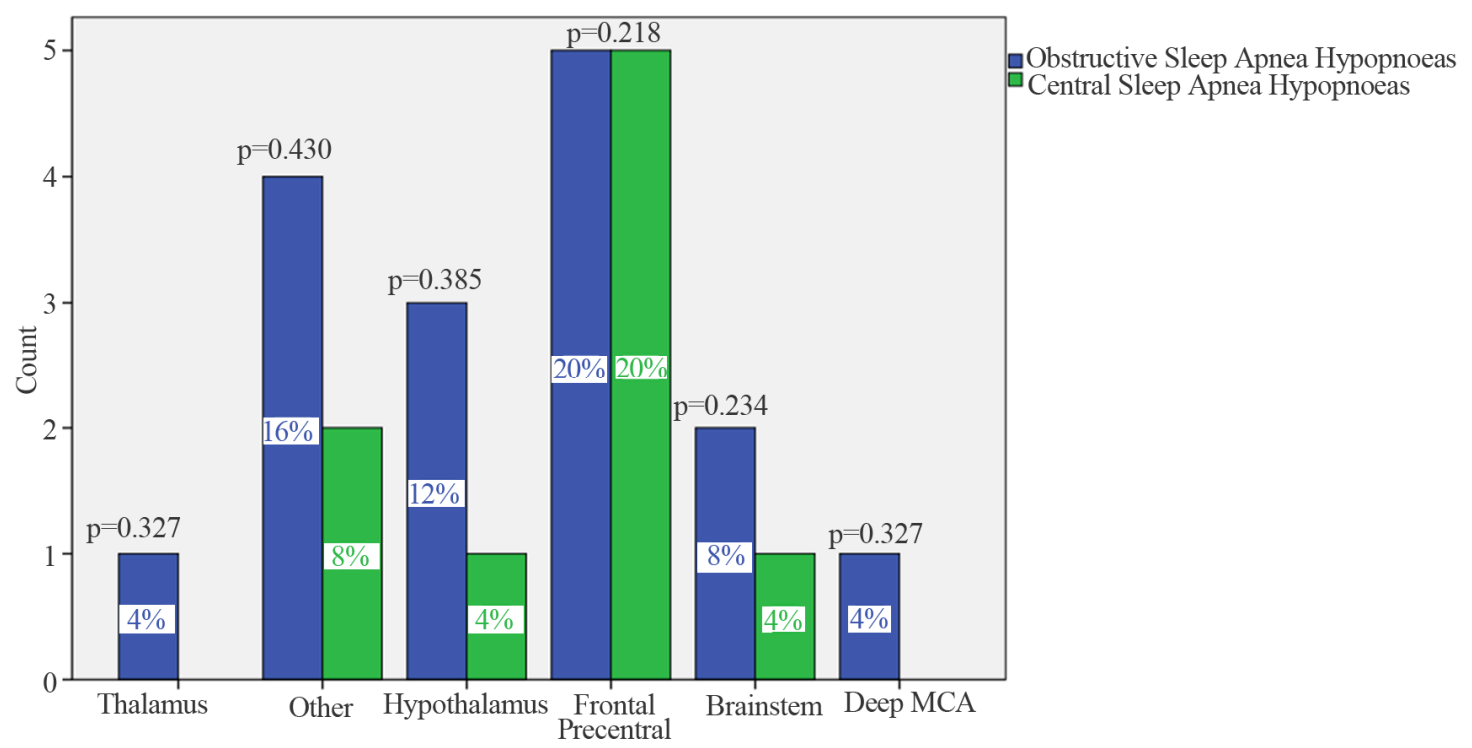

Figure 1. Sites of brain lesions so as to MRI findings. $p$ values so as to $\chi^{2}$ test. Comparisons are made between OSAHs and CSAHs. Significance is set at 0.05 . On x-axis are reported the list of locations of brain lesions; on Y-axis is reported the count of cases. In blue are cases that presented predominantly obstructive events $(p O S A H)$, and in green are cases who presented predominantly central events $(p \mathrm{CSAH})$ at PSG after 4 months of stroke onset. 
Table 1. Patients demographic data, clinical characteristics, risk factors for stroke, PSG data, and comparisons between OSAHs and CSAHs.

\begin{tabular}{|c|c|c|c|c|}
\hline & & $p \mathrm{OSAH} \mathrm{N}=16$ & $p \mathrm{CSAH} \mathrm{N}=10$ & p values $\#$ \\
\hline \multirow[t]{2}{*}{ Demographics } & Age mean \pm SD & $60 \pm 12$ & $72 \pm 11$ & 0.022 \\
\hline & Males n (\%) & $12(75)$ & $8(80)$ & 0.087 \\
\hline \multirow[t]{10}{*}{ Clinical characteristics } & $\mathbf{N I H}-\mathbf{S S}$ at entry mean $\pm \mathrm{SD}$ & $5.1 \pm 3.6$ & $3.6 \pm 2.45$ & 0.249 \\
\hline & $\mathrm{NIH}-\mathrm{SS}$ at discharge mean \pm SD & $2.2 \pm 1.9$ & $1.3 \pm 1.8$ & 0.352 \\
\hline & BMI mean \pm SD & $27.4 \pm 5.3$ & $28.4 \pm 4$ & 0.600 \\
\hline & $\mathrm{AHI}$ mean $\pm \mathrm{SD}$ & $15.3 \pm 8.7$ & $15.3 \pm 8.2$ & 0.992 \\
\hline & BMI $\geq 30 \mathrm{n}(\%)$ & $3(8.8)$ & $4(11.8)$ & 0.230 \\
\hline & ESS mean \pm SD & $7.7 \pm 4.6$ & $6.8 \pm 4.9$ & 0.645 \\
\hline & Symptoms other than Daily Sleepiness n (\%) & $10(62.5)$ & $7(70)$ & 0.517 \\
\hline & Days between stroke and PSG mean \pm SD & $147.1 \pm 63.2$ & $113.5 \pm 18.5$ & 0.249 \\
\hline & Obstruction of the upper airways n (\%) & $8(26.7)$ & $4(13.3)$ & 0.616 \\
\hline & Increase in pharyngeal tissue $\mathrm{n}(\%)$ & $4(11.8)$ & $3(8.8)$ & 0.562 \\
\hline \multirow[t]{11}{*}{ Risk factors for stroke } & Hypertension n (\%) & $11(68.8)$ & $8(80)$ & 0.438 \\
\hline & Smoke n (\%) & $10(62.5)$ & $5(50)$ & 0.412 \\
\hline & Atrial fibrillation n (\%) & $5(31.3)$ & $5(50)$ & 0.293 \\
\hline & ICA stenosis n (\%) & $7(43.8)$ & $2(20)$ & 0.210 \\
\hline & Diabetes n (\%) & $5(31.3)$ & $2(20)$ & 0.438 \\
\hline & Previous TIA n (\%) & $3(18.8)$ & $2(20)$ & 0.657 \\
\hline & Ischemic heart disease $\mathbf{n}(\%)$ & $5(31.3)$ & $3(30)$ & 0.648 \\
\hline & Patent foramen ovale $\mathrm{n}(\%)$ & $4(25)$ & $1(10)$ & 0.343 \\
\hline & Hyperomocisteinemia n (\%) & $2(12.5)$ & $1(10.0)$ & 0.677 \\
\hline & Hypercholesterolemia n (\%) & $12(75)$ & $6(60)$ & 0.352 \\
\hline & Congestive heart failure $\mathrm{n}(\%)$ & $2(12.5)$ & $0(0)$ & 0.369 \\
\hline \multirow[t]{4}{*}{ Causes of stroke } & Embolic & $9(56.3)$ & $5(50)$ & 0.536 \\
\hline & Micro vascular & $6(37.5)$ & $6(37.5)$ & 0.210 \\
\hline & Large vessels & $1(6.3)$ & $1(10)$ & 0.234 \\
\hline & Unknown & $0(0)$ & $2(20)$ & 0.138 \\
\hline \multirow[t]{6}{*}{ Sites of brain lesions } & Thalamus & $1(6.3)$ & 0 & 0.327 \\
\hline & Hypothalamus & $3(18.8)$ & $1(10)$ & 0.385 \\
\hline & Frontal pre-central & $5(31.3)$ & $5(50)$ & 0.218 \\
\hline & Deep MCA & $1(6.3)$ & $0(0)$ & 0.327 \\
\hline & Brainstem & $2(12.5)$ & $1(10)$ & 0.234 \\
\hline & Other & $4(25)$ & $2(20)$ & 0.430 \\
\hline \multirow[t]{7}{*}{ PSG data } & Total Sleep Time (in minutes) mean \pm SD & $344.44 \pm 134.3$ & $333 \pm 122$ & 0.829 \\
\hline & Total Sleep Period (in minutes) mean \pm SD & $427.7 \pm 137.1$ & $496.5 \pm 96.4$ & 0.179 \\
\hline & Sleep Efficiency Index mean \pm SD & $74.3 \pm 19$ & $63.6 \pm 26.5$ & 0.242 \\
\hline & Arousals/h sleep (in thousands) mean \pm SD & $39 \pm 18$ & $42.5 \pm 14.8$ & 0.601 \\
\hline & Arrhythmias/h sleep mean $\pm \mathrm{SD}$ & $73.8 \pm 167.8$ & $237 \pm 272.9$ & 0.070 \\
\hline & ODI mean \pm SD & $15.6 \pm 11$ & $13.9 \pm 6.5$ & 0.672 \\
\hline & ${ }^{*} \chi^{2}$, Fisher exact Test or Anova as appropriate. & e is set at 0.05 & & \\
\hline
\end{tabular}

pOSAH = predominantly obstructive sleep apnoea-hypopnoea; $p$ CSAH = predominantly central sleep apnoea-hypopnoea; $\mathrm{SD}=$ standard deviation; $\mathrm{AHI}=$ apnea/hypopnea index; ANOVA = analysis of variance; BMI = body mass index; ESS = Epsworth Sleep Scale; ICA = internal carotid artery; NIH-SS = National Institute of Health Stroke. Scale; TIA = transient ischaemic attack. ODI = oxygen desaturation index. 
Table 2. Significant correlations between clinical findings or site of cerebral lesion, and PSG data: differences between $p$ OSAH and $p$ CSAH cases.

\begin{tabular}{|c|c|c|c|c|c|c|}
\hline & & & \multicolumn{2}{|c|}{ pOSAH } & \multicolumn{2}{|c|}{ pCSAH } \\
\hline & & PSG data & $\begin{array}{l}\text { Correlation } \\
\text { coefficient }\end{array}$ & $\underset{\text { value }^{\#}}{\mathrm{p}}$ & $\begin{array}{l}\text { Correlation } \\
\text { coefficient }\end{array}$ & $\underset{\text { value }}{\mathrm{p}}$ \\
\hline \multirow[t]{10}{*}{ Clinical findings } & AHI & N. of Obstructive events & 0.827 & 0.000 & 0.584 & 0.077 \\
\hline & & ODI & 0.949 & 0.000 & 0.527 & 0.117 \\
\hline & Age & Sleep efficiency Index & -0.508 & 0.045 & 0.190 & 0.600 \\
\hline & Time from stroke onset & Total Sleep Time & -0.588 & 0.017 & -0.358 & 0.310 \\
\hline & & Total Sleep Period & -0.519 & 0.039 & 0.576 & 0.082 \\
\hline & & Sleep efficiency Index & -0.112 & 0.680 & -0.711 & 0.021 \\
\hline & & ODI & 0.308 & 0.247 & 0.673 & 0.033 \\
\hline & NIH-SS at entry & Arousals/h sleep & 0.509 & 0.044 & 0.549 & 0.100 \\
\hline & ODI & N. of Obstructive events & 0.675 & 0.004 & 0.231 & 0.521 \\
\hline & Arrhythmias/h sleep & Total Sleep Period & 0.345 & 0.190 & 0.648 & 0.043 \\
\hline Location of brain lesion & Other & Total Sleep Period & 0.501 & 0.048 & 0.337 & 0.341 \\
\hline
\end{tabular}

\#Spearman Rho. Significance is set at 0.05. $p$ OSAH $=$ predominantly obstructive sleep apnoea-hypopnoea; $p$ CSAH $=$ predominantly central sleep apnoea-hypopnoea; AHI = apnea/hypopnea index; ODI = oxygen desaturation index; ESS = Epsworth Sleep Scale; NIH-SS = National Institute of Health Stroke Scale.

such as a BMI $>30$, a condition has been reported to be associated with an increased deposition of fat in lateral pharyngeal wall [18]. This observation has suggested that the predominance of CSAH over OSAH might be just phenoltypical, i.e. in certain cases the airway obstruction is combined with a $\mathrm{PaCO}_{2}$ rising over the ventilatory recruitment threshold, with consequent inhibition of central drives to breath [16,19] (Figure 2). If the hypothesis is true, among cases with post stroke sleep disordered breathings are included in at least 3 different subgroups, i.e. cases with obstructive events who terminate the obstruction thank to arousals (Figure 2(a)), cases with obstructive events who do not arise and instead enter in a loop gain $>1$ with consequent alternation of obstructive and central events (Figure 2(b)), and cases with central events due to the direct effect of stroke on the breathing network (Figure 2(c)). The question rises whether clinical and/or diagnostic parameters are able to predict who will end their apnea with arousal, and/or those who will not arise from sleep and alternate obstructive to central sleep events. The question is relevant considering that patients with high loop gain are those who do not respond to CPAP, the only treatment option that so far has been demonstrated to be beneficial for both breathing and clinical outcome of cases affected by sleep disordered breathings after stroke [20-24].

The main differences we found between the two groups were from correlation analysis. As opposed to cases affected by $p \mathrm{OSAH}$, in patients with $p \mathrm{CSAH}, \mathrm{AHI}$ did not correlate to ODI, suggesting that they did not desaturate proportionally to the severity of their breathing disturbance during sleep. In the group with $p \mathrm{OSAH}$, time interval from stroke onset was inversely related to both TST and TSP; in $p$ CSAH cases, time interval from stroke onset was inversely correlated with the SE index, as if time from stroke onset has a negative influence on the quality of sleep and on its duration. Evidences have shown that stroke can cause depression, and that depression increases the CAP [25-28], it is therefore possible that conditions such as post stroke depression, have an effect on patients' CAP, regardless they are affected by $p \mathrm{OSAH}$ or by $p \mathrm{CSAH}$.

A fourth mechanism therefore might concur in determining the type of SDB after stroke, that is through a negative influence on patients' microstructure of sleep $[29,30]$. Unfortunately we are not able to either confirm or deny these hypothesises because we do not have data on the cycling alternating patterns (CAP) rate, nor we test the depression.

The present study has several limitations, consisting mainly in the small sample size, in the absence of quantitative data on both the breathing airways' patency and on patients' microstructure of sleep. Nonetheless, at our best knowledge it is the first study investigating differences in the clinical, PSG and in location of brain damage between patients presenting $p \mathrm{OSAH}$ and those presenting $p$ CSAH at PSG.

Sleep disordered breathings after stroke have been demonstrated to be deleterious for patients' clinical outcome. Their appropriate treatment is therefore mandatory. 


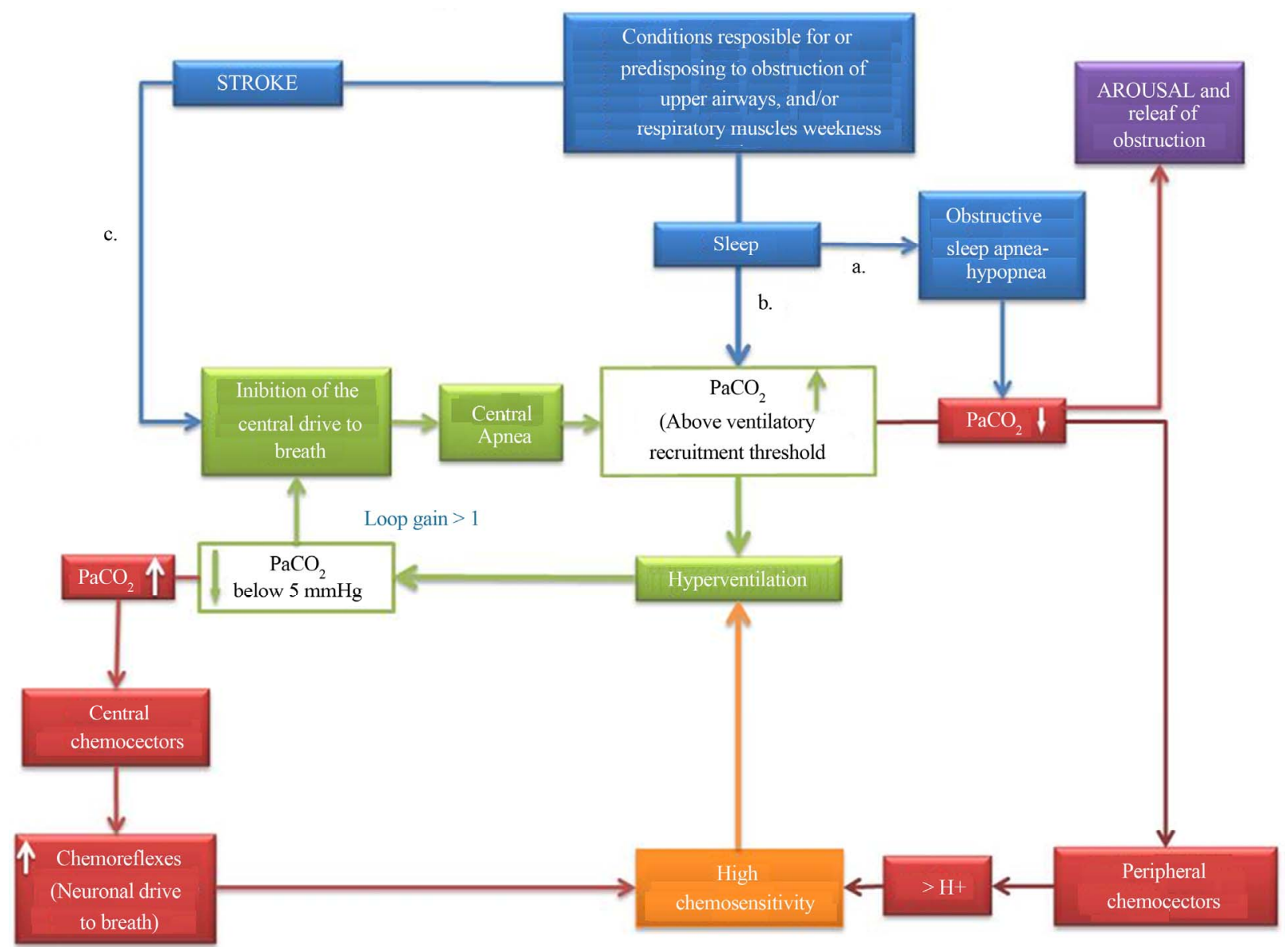

Figure 2. Possible mechanisms responsible for sleep disordered breathings after stroke. a. Obstructive sleep apnea-hypopnea (OSAH) can precede stroke, or be caused by the effect of stroke on upper airways' caliber; the apnea is generally terminated by arousal from sleep and consequent dilation of upper airways muscles. b. In some instances the $\mathrm{PaCO}_{2}$ can rise above the ventilatory recruitment threshold, giving origin to a loop gain $>1$ and the consequent alternating presence of OSAH and central sleep apnea-hypopnea (CSAH); elevated levels of $\mathrm{PaCO}_{2}$ can be also detected in stroke patients in concomitance with either metabolic or mechanical disturbances, such as weakness of respiratory muscles. In the case of $\mathrm{PaCO}_{2}$ levels above the ventilatory recruitment threshold, the physiological loop gain equal to 1 can be altered, with the consequent alternating presence of OSAH and CSAH; An altered loop gain can result also from high chemo-sensitivity, either primary or induced by chemical stimuli consequent to $\mathrm{PaO}_{2}$ alterations (drown respectively in orange and in red). c. CSAH can be the direct consequence of a damage to the central neuronal drive to breath.

In order to maximise the effectiveness of treatments, they must be personalised. Given that it has been demonstrated that not only CAP is influenced by sleep disorders but, in turn, it can modulate the occurrence of sleep-related events, the study of stroke patients' sleep microstructure is necessary to understand the pathophysiology of sleep disordered breathing after stroke, and to better target appropriate treatment options.

\section{ACKNOWLEDGEMENTS}

Funded by Sapienza, University of Rome on year 2010. Grant n. C26A10E3ST.

\section{REFERENCES}

[1] Johnson, K.G. and Johnson, D.C. (2010) Frequency of sleep apnea in stroke and TIA patients: A meta-analysis. Journal of Clinical Sleep Medicine, 6, 131-137.

[2] Bassetti, C. and Aldrich, M.S. (1999) Sleep apnea in acute cerebrovascular diseases: Final report on 128 patients. Sleep, 22, 217-223.

[3] Sacchetti, M.L., Mascio, M.T.D., DellaMarca, G., Minni, A., Ottaviani, S., Toni, D. and Fiorelli, M. (2013) Sleep disordered breathing after stroke: Clinical profile of patients with obstructive- as opposed to central-sleep apnea. Journal of Sleep Disorders \& Therapy, 2, 113-116.

[4] Muir, K.W., Weir, C.J., Murray, G.D., Povey, C. and Lees, K.R. (1996) Comparison of neurological scales and scoring systems for acute stroke prognosis. Stroke, 27, 18171820. doi:10.1161/01.STR.27.10.1817

[5] Pezzella, F.R., Picconi, O., De Luca, A., Lyden, P.D. and Fiorelli, M. (2009) Development of the Italian version of the National Institutes of Health Stroke Scale: It-NIHSS. Stroke, 40, 2557-2559. 
doi:10.1161/STROKEAHA.108.534495

[6] Madden, K.P., Karanjia, P.N., Adams, H.P. and Clarke, W.R. (1995) Accuracy of initial stroke subtype diagnosis in the TOAST study. Trial of ORG 10172 in Acute Stroke Treatment. Neurology, 45, 1975-1979. doi:10.1212/WNL.45.11.1975

[7] Johns, M.W. (1991) A new method for measuring daytime sleepiness: The Epworth sleepiness scale. Sleep, 14, 540545.

[8] Thorpy, M.J. (American Academy of Sleep Medicine) (2005) International classification of sleep disorders. 2nd Edition, Diagnostic and Coding Manual American Academy of Sleep Medicine, Westchester.

[9] Kushida, C.A., Littner, M.R., Morgenthaler, T., Alessi, C.A., Bailey, D., Coleman, J., Friedman, L., Hirshkowitz, M., Kapen, S., Kramer, M., Lee-Chiong, T., Loube, D.L., Owens, J., Pancer, J.P. and Wise, M. (2005) Practice parameters for the indications for polysomnography and related procedures: An update for 2005. Sleep, 28, 499-521.

[10] Iber, C.A., Chesson, A. and Quan, S.F (The American Academy of Sleep Medicine) (2007) The AASM manual for the scoring of sleep and associated events: Rules, terminology and technical specifications.

[11] Bonnet, M., et al. (1992) "EEG arousals: Scoring rules and examples: A preliminary report from the Sleep Disorders Atlas Task Force of the American Sleep Disorders Association. Sleep, 15, 173-184.

[12] Guilleminault, C., Connolly, S.J. and Winkle, R.A. (1983) Cardiac arrhythmia and conduction disturbances during sleep in 400 patients with sleep apnea syndrome. The American Journal of Cardiology, 52, 490-494. doi:10.1016/0002-9149(83)90013-9

[13] Lee, M.C., Klassen, A.C., Hearney, L.M. and Perch, J.A. (1976) Respiratory rate and pattern disturbances in acute brain stem infarction. Stroke, 7, 382-385. doi:10.1161/01.STR.7.4.382

[14] Levin, B.E. and Margolis, G. (1977) Respiration seconddary to a unilateral brain stem infarction. Annals of Neurology, 1, 583-586. doi:10.1002/ana.410010612

[15] Askenasy, J.M. and Goldhamer, I. (1988) Sleep apnea as a feature of bulbar stroke. Stroke, 19, 637-639. doi:10.1161/01.STR.19.5.637

[16] Parra, O., Arboix, A., Bechich, S., García-Eroles, L., Montserrat, J.M., López, J.A., Ballester, E., Guerra, J.M. and Sopeña, J.J. (2000) Time course of sleep-related breathing disorders in first-ever stroke or transient ischemic attack. American Journal of Respiratory and Critical Care Medicine, 161, 375-380. doi:10.1164/ajrccm.161.2.9903139

[17] Bassetti, C., Aldrich, M.S. and Quint, D. (1997) Sleep disordered breathing in patients with acute supra- and infratentorial stroke: A prospective study of 39 patients. Stroke, 28, 1765-1772. doi:10.1161/01.STR.28.9.1765

[18] Shelton, K.E., Gay, S.B., Hollowell, D.E., Woodson, H. and Suratt, P.M. (1993) Mandible enclosure of upper airway and weight in obstructive sleep apnea. American Review of Respiratory Disease, 148, 195-200. doi:10.1164/ajrccm/148.1.195
[19] Dziewas, R., Humpert, M., Hopmann, B., Kloska, S.P., Lüdemann, P., Ritter, M., Dittrich, R., Ringelstein, E.B., Young, P. and Nabavi, D.G. (2005) Increased prevalence of sleep apnea in patients with recurring ischemic stroke compared with first stroke victims. Journal of Neurology, 252, 1394-1398. doi:10.1007/s00415-005-0888-7

[20] Levy, P. and Pepin, J.L. (2011) CPAP treatment of sleep apnoea in the early phase of stroke: Growing evidence of effectiveness. European Respiratory Journal, 37, 997999. doi:10.1183/09031936.00182810

[21] Parra, O., Sánchez-Armengol, A., Bonnin, M., Arboix, A., Campos-Rodríguez, F., Pérez-Ronchel, J., Durán-Cantolla, J., de la Torre, G., González Marcos, J.R., de la Peña, M., Carmen Jiménez, M., Masa, F., Casado, I., Luz Alonso, M. and Macarrón, J.L. (2011) Early treatment of obstructive apnoea and stroke outcome: A randomised controlled trial. European Respiratory Journal, 37, 1128-1136. doi:10.1183/09031936.00034410

[22] Sands, S.A., Edwards, B.A., Kee, K., Turton, A., Skuza, E.M., Roebuck, T., O’Driscoll, D.M., Hamilton, G.S., Naughton, M.T. and Berger, P.J. (2011) Loop gain as a means to predict a positive airway pressure suppression of cheyne-stokes respiration in patients with heart failure. American Journal of Respiratory and Critical Care Medicine, 184, 1067-1075. doi:10.1164/rccm.201103-0577OC

[23] Ryan, C.M., Bayley, M., Green, R., Murray, B.J. and Bradley, T.D. (2011) Influence of continuous positive airway pressure on outcomes of rehabilitation in stroke patients with obstructive sleep apnea. Stroke, 42, 10621067. doi:10.1161/STROKEAHA.110.597468

[24] Martinez-Garcia, M.A., Soler-Cataluna, J.J., EjarqueMartinez, L., Soriano, Y., Roman-Sanchez, P., Illa, F.B., Canal, J.M. and Duran-Cantolla, J. (2009) Continuous positive airway pressure treatment reduces mortality in patients with ischemic stroke and obstructive sleep apnea: A 5-year follow-up study. American Journal of Respiratory and Critical Care Medicine, 180, 36-41. doi:10.1164/rccm.200808-13410C

[25] Farina, B., Della Marca, G., Grochocinski, V.J., Mazza, M., Buysse, D.J., Di Giannantonio, M., Francesco Mennuni, G., De Risio, S., Kupfer, D.J. and Frank, E. (2003) Microstructure of sleep in depressed patients according to the cyclic alternating pattern. Journal of Affective Disorders, 77, 227-235. doi:10.1016/S0165-0327(02)00147-7

[26] Paolucci, S. (2008) Epidemiology and treatment of poststroke depression. Journal of Neuropsychiatric Disease and Treatment, 4, 145-154.

[27] Paolucci, S., Antonucci, G., Grasso, M.G., Morelli, D., Troisi, E., Coiro, P., De Angelis, D., Rizzi, F. and Bragoni, M. (2011) Post-stroke depression, antidepressant treatment and rehabilitation results. A case-control study. Cerebrovascular Diseases, 12, 264-271. doi: $10.1159 / 000047714$

[28] Hackett, M.L., Anderson, C.S., House, A. and Xia, J. (2008) Interventions for treating depression after stroke. Cochrane Database of Systematic Reviews, 4, CD003437.

[29] Thomas, R.J., Terzano, M.G., Parrino, L. and Weiss, J.W. (2004) Obstructive sleep-disordered breathing with a dominant cyclic alternating pattern-A recognizable 
polysomnographic variant with practical clinical implications. Sleep, 27, 229-234.

[30] Parrino, L., Ferri, R., Bruni, O. and Terzano, M.G. (2012)
Cyclic alternating pattern (CAP): The marker of sleep instability. Sleep Medicine Reviews, 16, 27-45.

doi:10.1016/j.smrv.2011.02.003 